\title{
121. On the Tea Tannin in Green Tea
}

\author{
By Michiyo Tsujimura \\ Zissen Women's College, Tokyo, Japan \\ (Comm. by K. Goтo, м.J.A., Oct. 12, 1960)
}

The tannin substance in tea (Thea sinensis L.) has frequently been investigated by many researchers, but their opinions are so contradictory in many respects. ${ }^{123}$

In 1929, the present author isolated tea catechin I (1-epicatechin) from Japanese green tea in crystalline state ${ }^{3)}$ and in 1934 , tea catechin II (1-epigallocatechin) was isolated. ${ }^{4)}$

The present author succeeded in 1935 in isolating tea tannin $\mathrm{I}^{5)}$ in a crystalline state, which was proved to be the galloyl ester of tea catechin I (1-epicatechin gallate).

A. E. Bradfield isolated the second tea tannin ${ }^{6)}$ which represented the galloyl ester of tea catechin II (1-epigallocatechin gallate), and it was also isolated afterwards by the present author.")

These are all levorotatory as shown in the following list.

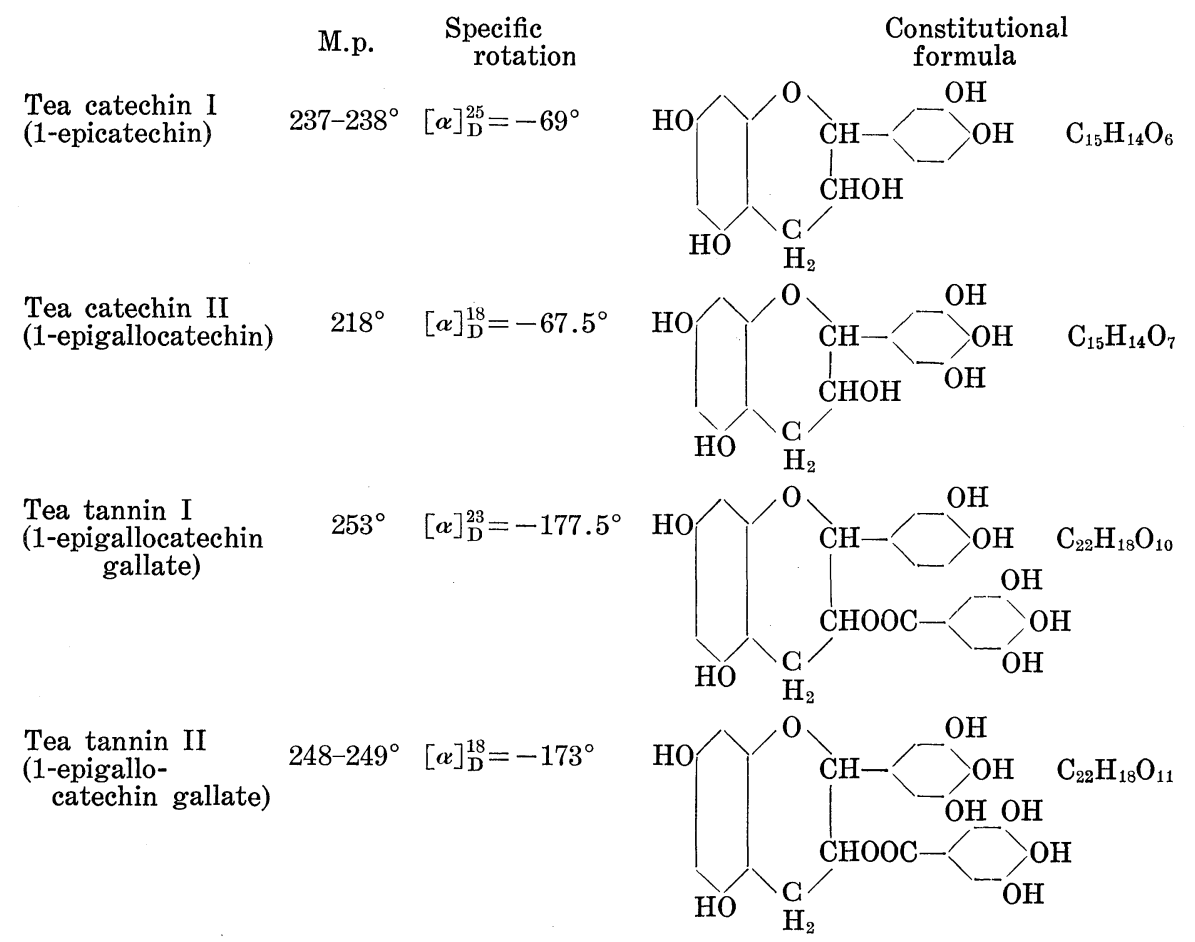

Besides these four substances, the existence of ( \pm )-catechin and $( \pm)$-gallocatechin was recognized in Ceylon green tea by means of 
paper chromatography by A. E. Bradfield. E. A. H. Roberts also recognized $(+)$-catechin and (+)-gallocatechin by the method of paper chromatography together with the above-mentioned four substances. ${ }^{8)}$

The author has made repeated investigations with various kinds of Japanese green tea, which having been manufactured through steaming method, by paper chromatography, but found out every time only the spots for the above-mentioned four substances, the chromatograms are shown in the annexed photographs. From this result it may be concluded that, the tea tannin extracted from Japanese green tea consists of the above-mentioned four substances under different proportion.

\section{Chromatogram}

Two dimensional paper chromatograms of tea tannin in Japanese green tea

1. Tea catechin $\mathrm{I}$

$1^{\prime}$. Tea tannin I



No. III
2. Tea catechin II

$2^{\prime}$. Tea tannin II

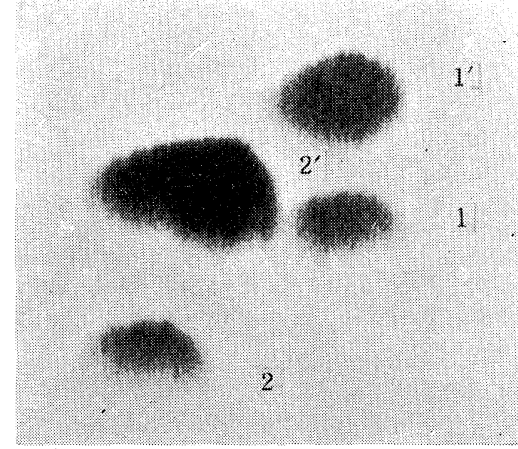

No. II

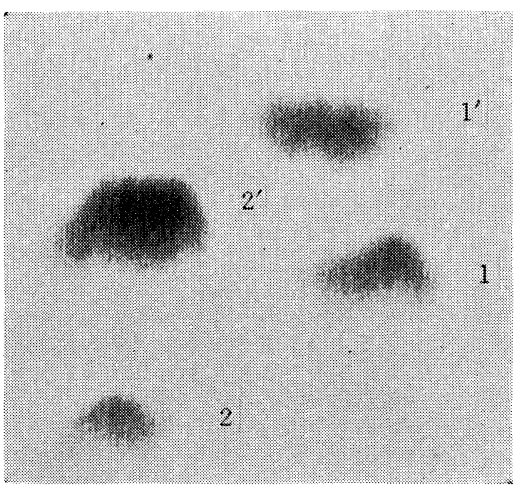

No. IV (gyokuro)

Water + saturated phenol

* The number of chromatograms corresponds to the material number.

\section{Experimental}

Material of Japanese green tea

No. I superior class of green tea (sencha) 
No. II common class

No. III inferior class

No. IV sweet green tea (gyokuro)

Preparation of sample. Every material (20 gr) was extracted with ethyl acetate $(200 \mathrm{cc})$ containing $10 \%$ water at $60^{\circ}$ for one hour. After the solvent was evaporated under reduced pressure, the residue was extracted with water. The aqueous extract was treated with 2-3 drops of neutral lead acetate solution to remove impurities. The filtrate was then added with 10\% sulphuric acid and filtered. From the filtrate, the tannin substances were again extracted with ethyl acetate by repeated shaking. The ethyl acetate solution was then evaporated down to a small bulk and used directly for the paper chromatography.

\section{References}

1) J. Dekker: Die Gerbstoffe, 410 (1913).

2) J. J. B. Deuss: Rec. Trav. Chim., 42, 496 (1923).

3) M. Tsujimura: Sci. Pap. I. P. C. R., 10, 253 (1929).

4) —: Idem, 24, 149 (1934).

5) —: Idem, 26, 186 (1935).

6) A. E. Bradfield: Biochim. Biophys. Acta, 4, 441 (1950).

7) M. Tsujimura: J. Agr. Chem. Soc. Japan, 29, 407 (1955); 33, 914 (1959).

8) E. A. H. Roberts: Biochem. J., 49, 414 (1951). 